\title{
LOS PLENOS PODERES DE GABRIEL GARCÍA MÁRQUEZ: ASOMBROS Y CONJETURAS
}

\author{
Héctor Soto
}

\begin{abstract}
Resumen: En el año de su muerte, y a partir de diversos datos de la biografía del Premio Nobel de Literatura 1982, muchos de ellos extremadamente novelescos, este ensayo intenta identificar algunas constantes de su obra y también algunos rasgos de su carácter. A pesar de no ser un autor propiamente "político", corresponde recordar que García Márquez fue un escritor muy marcado por la Guerra Fría y con una evidente debilidad por el poder, en sus expresiones menos idealistas y más fácticas.

Palabras Clave: Gabriel García Márquez, literatura latinoamericana, poder, realismo mágico, Cien años de soledad, El otoño del patriarca, Fidel Castro.
\end{abstract}

RECIBIDO: agosto 2014; ACEPTADO: agosto 2014.

\section{THE FULL POWERS OF GABRIEL GARCÍA MÁRQUEZ: WONDER AND CONJECTURE}

\begin{abstract}
In the year of his death, and from different details of the life of the winner of the 1982 Nobel Prize in Literature, many of them quite bizarre, this article attempts to identify some constants in his work and also some traits of his character. Despite the fact that he was not a specifically "political" writer, one must bear in mind
\end{abstract}

HÉctor Soto. Abogado, periodista, crítico de cine. Columnista político y asesor de la dirección del diario La Tercera. Autor de Una vida crítica, 45 años de cinefilia (Santiago: Ediciones Universidad Diego Portales, 2013). Email: hector.soto@ latercera.cl 
that Garcia Márquez was much influenced by the Cold War, with a marked weakness for power in his less idealistic and more factual expressions.

Keywords: Gabriel García Márquez, Latin American literature, power, magical realism, One Hundred Years of Solitude, The Autumn of the Patriarch, Fidel Castro.

RECEIVED: August 2014; ACCEPTED: August 2014.

\section{$\mathrm{L}$}

os biógrafos, los directores de cine, los psiquiatras y los periodistas que escriben obituarios nos han acostumbrado a pensar la vida de las personas como si se tratase de una historia. Una historia con planteamiento, desarrollo y desenlace. En unos pocos casos, incluso, presentan la vida como una epopeya, esto es, como la consecución de un destino heroico al cual el sujeto estuvo llamado desde el momento del nacimiento.

Pero es más o menos obvio que las cosas no son así. Aunque puedan serlo, las vidas por lo general no son historias redondas. No tienen una sola trama. Y a veces tampoco un único sentido. Una vida puede parecerse, como se ha dicho tantas veces, a un viaje, pero - concedámoslo- es un viaje fragmentario, discontinuado, con avances, con retrocesos, con períodos en blanco, con desvíos y extravíos.

Estas son sólo prevenciones para hablar de la vida y de la obra de un escritor excepcional y complejo: Gabriel García Márquez. La suya no es una figura que sea fácil capturar de buenas a primeras. Pertenece a lo mejor de las letras latinoamericanas, pero también a la picaresca del exilio latinoamericano en Europa y a muchos de los desarrollos del conflicto político en la región. García Márquez, Premio Nobel de Literatura 1982, es un personaje encantador, divertido, evasivo, juguetón, generoso, inteligente, inspirado, receptivo y muchas cosas más. Pero ni uno de estos atributos por sí solo, y ni siquiera todos ellos en conjunto, es capaz de soportarlo o definirlo sin más. Incluso en una vida tan historiada y compuesta como la de García Márquez, donde los datos duros se mezclan con la especulación y donde lo que a veces no pudo el voluntarismo sí lo pueden las máscaras, su biografía siempre esconderá un trasfondo de misterio irreductible. Tal vez haya que aceptarlo. Es lo más sencillo y sensato. $Y$ hay que hacerlo, porque en mayor o menor medida así son casi todas las vidas. 
Quien se quede con la espléndida biografía de García Márquez escrita por el académico inglés Gerald Martin ${ }^{1}$, que estuvo hablando con el escritor, con sus amigos y con testigos de su carrera periodística y literaria durante más de quince años, es natural que se termine comprando por anticipado la idea del sujeto convocado por las letras desde mucho antes de que él mismo se planteara convertirse en escritor. ¿Cuántos niños habrá en América Latina que reciben como regalo un diccionario el día de su cumpleaños? Se diría que muy pocos. Pocos, aun en Colombia, donde la preocupación por los asuntos de la gramática, la ortografía, la filología, la prosodia, la sintaxis o la lexicología merecieron más atención que en cualquier otra república latinoamericana. Fue en Colombia donde surgió la primera academia de la lengua de la región. Fue en Colombia donde se terminó hablando el mejor castellano de América Latina, si es que no del mundo. Fue también en esa nación donde no menos de cuatro presidentes de la república, un vicepresidente y varios otros magistrados publicaron sesudos y laboriosos compendios, diccionarios y tratados relacionados con las ortodoxias del habla y el buen decir. Todos ellos - destaca Enrique Krauze en una reseña de la biografía de Martin ${ }^{2}$ - provenían del bando conservador. Para los conservadores, la lengua no sólo fue la base o el piso sobre el cual habría de construirse la república, también era el puente de conexión con la España católica, eterna y adusta que correspondía replicar en la nación independiente.

Puede parecer raro que el idioma llegue a tener alcances políticos tan obvios. En Colombia, sin embargo, los tuvo y es revelador saber que los ancestros de García Márquez fueron parte de esas tensiones y disputas. El abuelo materno del escritor, el coronel Nicolás Márquez Mejías, nacido en 1864 y muerto en 1936, figura central en su biografía, fue un hombre que luchó en tres guerras civiles y que militó por el bando liberal en las huestes del general Uribe Uribe, uno de los pocos caudillos de la historia política colombiana. Además de militar, Uribe

${ }^{1}$ Gerald Martin, Gabriel García Márquez: Una vida (Barcelona: Debate, 2009).

2 Enrique Krauze, “Gabriel García Márquez. A la sombra del patriarca”, Letras Libres, noviembre de 2009. 
Uribe fue periodista, abogado, librero, traductor, diplomático y senador. Estuvo dos o tres veces en prisión y no es un dato menor que en una de ellas haya traducido escritos de Herbert Spencer y que en otra haya salido de la cárcel con el Diccionario abreviado de galicismos, provincialismos y correcciones de lenguaje. La obra, al parecer, no tuvo gran resonancia, pero de todos modos describe el intento de su autor por disputarle a sus enemigos políticos la agenda del idioma en el terreno donde los más puristas se planteaban. El general, además, los enfrentó en otros planos. Se cuenta que cuando estuvo en el Senado debió batirse en solitario contra sesenta senadores conservadores y que ese contrapeso fue el que con el tiempo lo llevó "a dar la palabra a los cañones". Debe haber sido un adversario temible y aguerrido durante la Guerra de los Mil Días (1899-1902) que, tras muchas barbaridades por lado y lado, concluyó en la llamada Paz de Neerlandia. El general salvó la vida y, aunque con menos protagonismo, siguió siendo parte de la escena política colombiana. Eso sí que lo asesinaron en 1904. Su lugarteniente, el coronel Márquez, lo sobrevivió 22 años y no es descaminado pensar, como sugiere Enrique Krauze, que al entregar a su nieto mayor un diccionario estaba siendo leal a la causa de su jefe. La causa de la lengua liberal. La mirada de Krauze es tajante: "En cualquier parte del mundo, el diccionario es un instrumento de saber. Pero en Colombia, de poder".

La vida de García Márquez es extremadamente novelesca. En realidad, se parece a la de sus personajes. El escritor nació en el seno de una familia empobrecida pero que todavía conservaba algunos de los signos de su prestigio, de sus glorias pasadas y de su poder. Entre esos signos estaba el enorme caserón de la familia en Aracataca, el pueblo donde García Márquez nació el 6 de marzo de 1927, y el respeto que todavía inspiraba el pasado militar de su abuelo, a la altura de los principales del pueblo. Don Nicolás se había convertido a principio de siglo en recolector local de impuestos. Aunque no era un hombre de fortuna, y aunque murió esperando la pensión prometida en el armisticio de la Guerra de los Mil Días que asumía como propia, Nicolás Márquez Mejías gozaba de cierta consideración.

Su figura es importante porque éste fue un niño más hijo de sus abuelos que de sus padres. Luisa Santiago, la madre, no se compró exactamente un pasaje al paraíso al contraer matrimonio con Gabriel 
Eligio García en la catedral de Santa Marta la mañana del 11 de junio de 1926. Por entonces, el marido era un joven extrovertido e impulsivo de unos 25 años, hijo ilegítimo, condición que en esos años y en esas latitudes imprimía carácter, y que con el tiempo se especializaría por su cuenta en los misterios de la homeopatía. De hecho, en varios momentos de su vida Gabriel Eligio antepuso a su apellido el título de doctor. Luisa Santiago lo conoció cuando llegó a su pueblo en condición de telegrafista. Venía huyendo de problemas en que se había metido en otras localidades y a pesar de su juventud ya había tenido varios hijos ilegítimos. Traía una carta de recomendación de un cura que era un antiguo conocido del coronel Márquez y por eso, porque lo contactó y porque el coronel simpatizó con él, éste lo presentó a su familia, en especial a su mujer y a su hija Luisa Santiago, quienes en ese momento estaban veraneando en Santa Marta. No tardó mucho tiempo en darse cuenta de que había cometido un error. El de la pareja no fue un amor a primera vista y cuando la relación se estableció el abuelo la resistió cuanto pudo. Su hija tenía 19 años, era bonita, había estudiado en un colegio católico distinguido y las expectativas de la familia eran casarla con alguien que efectivamente estuviera en un escalón social superior. No era el caso de este chico de color más bien oscuro, de pasado poco diáfano, de bonita voz y nada torpe con el violín, simpático y hablador como él solo, militante del Partido Conservador para mayor desgracia, que no estaba en condiciones de garantizar a la joven un futuro especialmente prometedor.

La verdad es que nunca pudo dárselo. Aunque era un experimentado seductor frente a cualquier mujer que se le cruzara en el camino, en el plano económico y laboral Gabriel Eligio jamás pudo estabilizarse o construir algo sólido. Trabajó como dependiente de farmacia durante un tiempo, después trató de independizarse varias veces en el mismo rubro, pero, al final, entre una farmacia y otra, entre un negocio aquí y otro allá, nunca pudo. Esta misma circunstancia lo convirtió en un personaje itinerante y en fuga permanente; siempre se estaba yendo o volviendo, acosado constantemente no sólo por acreedores sino también por amores defraudados que volvían a hacerse presente en su vida con no pocas cuentas pendientes por cobrar.

Ésta es la razón por la cual el niño no vivió con sus padres en su primera infancia. El padre ni siquiera estaba en el pueblo cuando nació 
el hijo y la madre, a los pocos meses, dejó el niño al cuidado del abuelo Nicolás y la abuela Tranquilina para retomar la relación con su marido en otro contexto y lejos de la mirada escéptica de la familia. Después vendrían otros diez hijos. Fueron once hermanos en total. No hubo día en que Luisa Santiago no sintiera en la mirada de sus padres el reproche de un matrimonio en el cual ella se obstinó, a pesar de todas las prevenciones y negativas del coronel. Ni él ni su mujer asistieron a la ceremonia. Gabriel García Márquez volvería a reencontrarse con su madre seis años después, cuando ella vuelve de Barranquilla. Martin describe la escena del reencuentro. El niño no conoce a su madre y las primeras palabras de ella son demoledoras: como el niño está muy desconcertado, le dice: “¿No vas a darle un abrazo a tu madre?”. Maestra en el manejo de la culpa, es una madre latinoamericana, al fin. ¿Quién debía abrazar a quién? Ella, que abandonó, o el niño, quien fue el abandonado.

Faltaban en ese momento dos años para que él perdiera al abuelo. Para entonces, en todo caso, el coronel ya había generado con el pequeño muchas complicidades y había impreso en su conciencia un espíritu autónomo y fabulador que lo acompañaría por el resto de su vida.

$\mathrm{Si}$ vale la pena repasar estos antecedentes familiares es porque dejaron huellas profundas en el escritor. Tanto en su carácter como en su obra. El coronel Márquez Mejías fue un personaje de proporciones. Aparte de los tres hijos que tuvo en su matrimonio con Tranquilina, se le conocieron otros nueve de madres distintas. Desde luego, el coronel ganó título no al interior de una organización militar amparada por la Constitución y las leyes, sino más bien al fragor de las muchas batallas que dio para violar y desconocer precisamente esa Constitución y esas leyes. Aunque se diga que participó en tres guerras civiles, hay razones para pensar que dos fueron alzamientos más o menos informales, lo bastante violentos para revolver el río pero no para desviarlo. Más seria fue la Guerra de los Mil Días, que levantó en armas al mundo rural colombiano a fines del siglo XIX y comienzos del XX. El hombre tenía heridas en su pasado. En uno de esos levantamientos luchó contra dos de sus propios hijos ilegítimos. Más grave que eso fue que cargara con el fantasma de un muerto a sus espaldas. El asunto fue confuso y los relatos, contradictorios. La pugna habría sido por una mujer. Al parecer, por el honor de una mujer, concretamente, que el coronel habría puesto en duda y en defensa del cual salió uno de los hijos. Unas versiones di- 
cen que hubo un duelo. Otras, harto menos épicas, que simplemente habría dado muerte a su adversario por la espalda. El coronel, en cualquier caso, varias veces según su nieto, le habló del peso que significaba cargar con un muerto en la espalda. El niño no sabía a qué se refería. Vino a intuirlo, a saberlo, a procesarlo, mucho tiempo después.

No obstante que Nicolás Márquez Mejías abrazó desde temprano la causa liberal, el hombre siempre fue muy autónomo en materia de creencias y convicciones. Iba a la iglesia con piadosa regularidad, se inclinaba ante la autoridad de los libros con una facilidad más bien rara entre los hombres de armas y entregó a su nieto una mirada del mundo que juntaba una fuerte autoestima con el recuerdo de sus campañas bélicas, arduos conocimientos sobre la misteriosa vida de los pájaros con el desprecio a las instituciones formales de la democracia y las estrecheces del presente con la supuesta opulencia de la Aracataca de los buenos tiempos. Ahí estaba la materia prima a partir de la cual García Márquez trabajaría su obra.

En términos de carácter, sin embargo, el escritor terminó pareciéndose quizás más al padre que al abuelo. La misma simpatía compradora de Gabriel Eligio, la misma capacidad para hacer una gran fiesta a partir de nada, el mismo desenfado para bailar, la misma extravagancia para vestir, el mismo orgullo para gozar de la vida con poco, a la manera del Caribe, en contraposición a la rigidez conservadora, castigadora y acartonada con que él asociaría siempre la vida en Bogotá.

El único rasgo que el escritor no asumió en la misma medida fue el donjuanismo de su padre, fuente de profundos dolores no sólo para su madre sino también para él, como hermano mayor de una familia numerosa: siete varones y cuatro mujeres. Aunque era naturalmente un seductor, García Márquez manejó esta variable con discreción. No fue un hombre de grandes amores en cada ciudad o en cada esquina. Fue más bien de pocos afectos pero intensos. A los quince años, se lo vinculó mucho a una mujer mayor, casada con un uniformado. Se le vio en su juventud en largas y agotadoras jornadas de juerga que invariablemente terminaban en bares y prostíbulos. La leyenda dice que incluso vivió en un burdel durante un período en que su economía tocó fondo. Pero muchos de sus amigos dicen que más se exaltaba cantando y rumbeando que acostándose con las putas. Y en los asuntos del corazón se caracterizó por ser un hombre extraordinariamente ordenado y lineal. 
No cualquiera "elige" a la mujer de su vida no más verla y cuando ella apenas es una niña, de apenas nueve o diez años, que fue lo que hizo con Mercedes Barcha Iguarán. No cualquiera la convierte en su amada a la distancia, cual Dulcinea del Toboso; no al menos en estos tiempos. No cualquiera vuelve a buscarla cuando juzga que ya está en estado de merecer. Más importante, no cualquiera la consigue, en cumplimiento de un libreto que él había escrito resueltamente muchos años antes. Otra anomalía más: no cualquiera tiene tan escaso contacto con su prometida o con su novia; en realidad, se conocían muy poco y apenas pololearon antes de casarse. En fin, no cualquiera permanece fiel y a su lado hasta el día de su muerte. Exactamente al revés de lo que había hecho su padre.

Gabriel García Márquez debe haber tenido unos 14 años cuando le dedicó este soneto ingenuo, un poco kitsch pero precioso ${ }^{3}$ :

Niña

Al pasar me saluda, y tras el viento
que da el aliento de su voz temprana,
en la cuadrada luz de mi ventana
no se empaña el cristal sino el aliento.

Es tempranera como la mañana, cabe en lo inverosímil como un cuento y mientras cruza el hilo del momento vierte su sangre blanca la mañana.

Si se viste de azul y va a la escuela nadie adivina si corre o vuela porque es como la brisa, tan liviana

que la mañana azul nadie precisa cuál de las tres que pasa es la brisa, cuál es la niña y cuál es la mañana.

\footnotetext{
${ }^{3}$ Martin, Gabriel García Márquez, 117.
} 
La determinación afectiva que mostró Gabriel García Márquez, su sentido de programación, por llamarlo de algún modo, también terminaría explicando con el tiempo otras facetas en la vida del escritor.

Nadie nace escribiendo como García Márquez. Esto, que es una de esas obviedades que dan vergüenza ajena no más se leen, es un dato que no hay que olvidar ante una prosa tan perfecta, tan musical y tan autónoma como la suya. García Márquez tardó efectivamente largos años en convertirse en García Márquez.

Tiene que haber sido un estudiante excepcional. Quizás no destacó mucho en el colegio jesuita San José de Barranquilla, donde sus compañeros lo recordaban como un alumno retraído, malo para los deportes, bueno para el dibujo y las caricaturas, y muy dado a luchar con la métrica componiendo poemas que nadie tomaba demasiado en serio. Después, gracias a una beca del gobierno, fue enviado a estudiar a Bogotá. No exactamente a la capital, sino a un colegio relativamente nuevo, abierto con voluntad modernizadora, el Liceo Nacional de Zapaquirá, establecimiento de excelencia, en cuyo internado el estudiante tímido del San José fue revelando sus habilidades y rasgos de carácter hasta convertirse en un alumno aventajado, divertido, un tanto libertino incluso, competente en los deportes y con marcada inclinación a las letras. Según cuenta Gerald Martin, el chico fue uno de los tres del colegio que acompañaron al rector a una entrevista con el Presidente de la República Alberto Lleras Camargo. Sería quizás el primer contacto suyo con un hombre de poder y no es casualidad que a partir de allí haya forjado una relación con él. Lleras era un político liberal de gran cultura y buena prosa que terminó visitando el colegio. El mismo año de la audiencia presidencial, García Márquez pronunció en nombre de su liceo un discurso de exaltación sobre Franklin D. Roosevelt con motivo del fin de la Segunda Guerra Mundial, que no sólo llamó la atención en el establecimiento, sino que fue parte de las noticias y de la conversación de la ciudad. Su planteamiento había sido que, tal como El Cid, también el Presidente fallecido ganaba batallas después de muerto.

Que haya ido a la Universidad Nacional a estudiar derecho no es raro. El perfil de la carrera era coincidente con las expectativas de su- 
peración depositadas por la familia en el primogénito, y la decisión de matricularse ahí fue una especie de transacción con el padre, alarmado con el desenfado parrandero, musical y sexual con el que el joven volvió a Sucre después de sus años en la capital. Qué tenía que hacer García Márquez en una escuela de derecho es un asunto que todavía necesita explicaciones. Eran los estudios que seguía la élite y que requerían todos cuantos tuvieran ambición política. El problema es que la profesión representaba exactamente el revés de todo cuanto García Márquez haría en su vida, y la incongruencia no tardaría en estallar. Para cuando eso ocurriera, sin embargo, el joven ya habría ganado experiencias que lo marcarían para siempre: nuevos amigos (entre los cuales estuvo Plinio Apuleyo Mendoza, hijo de un político colaborador de Gaitán, y Camilo Cienfuegos, mártir de la revolución cubana), participación en el "bogotazo" que siguió al asesinato del caudillo del ala más izquierdista del liberalismo, el político populista y próximo candidato presidencial Jorge Eliecer Gaitán (experiencia que compartió con Fidel Castro, con quien sin embargo en ese episodio nunca se topó) y, sobre todo, creciente adicción a la literatura a través de autores como Hemingway, Dos Passos, Faulkner, Hesse, Thomas Mann, los clásicos rusos del XIX y - su gran descubrimiento- Kafka. Acabada la conmoción generada por el crimen y la violenta reacción popular, con la universidad cerrada y la pensión donde residía incendiada, a García Márquez no le fue especialmente difícil cortar sus estudios en la Universidad Nacional y volvió a Cartagena con la vaga intención de proseguirlos en la universidad local. Pero ni él, que había aprobado el primer año en Bogotá, estaba muy convencido de hacerlo y el mejor pretexto para mantenerlos a trote lento (hizo de nuevo el segundo y se inscribió para el tercero) fue que muy pronto empezaría a colaborar en algunas publicaciones como columnista y redactor. En estas aguas sí que un aspirante a escritor podía desplegarse y navegar con cierta libertad en esos años.

Lo hizo extraordinariamente bien y desde muy temprano. Su primer hogar periodístico fue El Universal de Cartagena, diario de tendencia liberal al que llegó invitado por un intelectual, médico y escritor costeño. En corto tiempo se hizo de un nombre que los lectores comenzaron a identificar porque seleccionaba y comentaba con inteligencia una noticia del flujo informativo. Una nota del periódico publicada en 
marzo del $1949^{4}$ explicaba que García Márquez estaría ausente por un tiempo por problemas de salud y pedía la comprensión de los lectores. El diario destacaba su talento para seleccionar "con la innata pulcritud de periodista de gran estirpe", del heterogéneo montón de noticias, "las que pudiesen brindar un mejor alimento a los lectores matutinos". Su estilo - reconocía - se impuso rápidamente en nuestro medio. Tiene, para ello, a más de un cultivado buen gusto, recursos verdaderamente maestros, obtenidos en sus disciplinas de cuentista y novelista".

La verdad es que en estos planos todavía el joven redactor no tenía mucho que mostrar. Pero ya lo haría; era asunto de esperar unos pocos años. Mientras tanto, sus crónicas para El Universal y luego para $E l$ Heraldo de Barranquilla, donde escribió por años una columna titulada La Jirafa bajo el pseudónimo de Septimus, ofrecieron cinco años de una robusta producción periodística. No siempre fue periodismo puro. Muchas de estas columnas están enriquecidas por abundantes licencias literarias. Hay notas que son verdaderos cuentos. Y no es difícil intuir que estaba naciendo efectivamente el escritor.

Lo del periodismo le tomó muchos años. Unos doce en total, de los cuales los cinco últimos fueron en su mayor parte en el extranjero. Los comienzos fueron difíciles. Hubo períodos durante los cuales el escritor vivió poco menos que del aire, con semanas enteras al borde de la miseria fisiológica porque simplemente no tenía un peso en los bolsillos para comer. Sin embargo, sus amigos cuentan que nunca perdió el optimismo ni la bonhomía. No se quejaba. No enrostraba sus pellejerías a los demás. Era, al parecer, un asunto de dignidad personal. Podía no tener un céntimo en los bolsillos, pero su extravagancia caribeña pantalones gastados, chaquetas de cáñamo, camisas raídas y de colores fuertes - no transmitían la imagen de un perdedor, que es lo que en ese momento era, y por la inversa no dejaban de irradiar glamour.

Cuando dejó Colombia en 1955 ya era un periodista prominente, con razonable futuro por delante, y de indudable sensibilidad izquierdista. Estaba escribiendo, por lo demás, en plena Guerra Fría, cuando la neutralidad, como decía John Foster Dulles, secretario de Estado de los Estados Unidos, era inmoral. García Márquez no tomó partido frontalmente, pero estaba claro que su causa no era la de Dulles. Había dicho

${ }^{4}$ Gabriel García Márquez, Obra periodística Vol. 1 (Barcelona: Bruguera, 1981), 10 . 
que le reventaba el franquismo. Había tomado distancia — dicho sea en su homenaje - del populismo peronista e ironizó bastante de los alardes mesiánicos de Eva Perón repartiendo dinero en España o en Italia durante su gira europea. Quienes leyeron las crónicas y reportajes que hizo de sus viajes por los países de la Europa del Este y por la propia Unión Soviética deben haber tomado nota, más que de sus desencuentros con el capitalismo, de su esfuerzo por entender y salvar a los socialismos reales y a la gente común y corriente con que se relacionaba ${ }^{5}$.

Lo importante, en todo caso, es tener presente que no por sentir que había logrado finalmente afirmar bien los pies en el suelo periodístico aceptó posponer sus ambiciones literarias. En esto nunca se perdió. Todo lo contrario. Cuando el oficio ya le estaba comenzando a imponer ansiedades que interferían su dedicación a las letras, juzgó que había llegado el momento de hacer algunos cortes. Publicó su primera novela, La hojarasca, en una editorial pequeña. Decidió partir a Europa. Y, cosa rara, porque se estaba yendo, formalizó su compromiso matrimonial con Mercedes Barcha (la misma niña que no se sabía si era tal, si era brisa o era mañana), intuyendo seguramente - como apunta Gerald Martin - que si no establecía en ese momento un vínculo sólido a través de ella con Colombia perdería a su patria para siempre.

Llegó a París, y de ahí partió a Ginebra, como corresponsal extranjero encargado de cubrir la cumbre de los Cuatro Grandes celebrada en junio de 1955, diez años después de concluida la guerra, y que reunió a Anthony Eden (Inglaterra), Nikolai Bulganin (URSS), el Presidente Eisenhower (EE.UU.) y el primer ministro Edgar Faure (Francia). Después se fue a cubrir el Festival de Cine de Venecia, el mismo año en que Ordet, obra maestra de un legendario maestro del arte cinematográfico, Carl Theodor Dreyer, se llevó el León de Oro. Pero no era ésa su favorita, sino la cinta de quien él llamó un muchacho de 29 años con cara de futbolista - Franco Rossi—, el que había presentado a la competencia una cinta titulada Amici per la pelle y que recibió el día de su estreno la más larga ovación tributada por el público a una película de la muestra. Después cumpliría su sueño de cruzar el telón de acero viajando a Checoslovaquia y Polonia, pues sospechaba que la Guerra Fría imponía

${ }^{5}$ Hay una buena mirada a esos trabajos en Germán Alburquerque F., La trinchera letrada: Intelectuales latinoamericanos y Guerra Fría (Santiago: Ariadna Ediciones, 2001). 
demasiadas mentiras de contrabando y quería comprobar por sí mismo qué tan distintas y consistentes eran las supuestas verdades del Oeste y el Este. Luego se instaló en París, en la seguridad de que sus despachos para dos diarios colombianos - El Espectador y El Universal- le entregarían una base mínima para mantenerse. Esos eran sus planes, hasta que al cabo de pocos meses la beca periodística se acabó. A uno de los diarios lo cerraron y el otro dejó de circular. Con un agravante: para entonces el escritor ya se había vinculado sentimentalmente con una joven española, aspirante a actriz, —María Concepción "Tachia” Quintana, oriunda del país vasco-, en una relación que fue intensa, que tuvo sus dilemas y crisis, aborto incluido, y sobre la cual Martin le preguntaría a García Márquez mucho tiempo después, a fines de 1993. Seis meses antes Martin había entrevistado en París a Tachia y obtenido de ella un detallado relato de lo que fue ese affaire para ella. La respuesta de García Márquez, a la pregunta de si podían hablar del tema, fue corta y concluyente: "No". Ahí fue cuando le dijo que "toda persona tiene tres vidas, la pública, la privada y la secreta" ${ }^{\text {. Y }}$ le aclaró que de esta última no estaba dispuesto a hablar. Respetable.

La relación finalmente no pasó a mayores. Fue un idilio sin destino. Quien sí calificó para mejores horizontes fue el propio escritor, que ya tenía en mente su segunda novela y siguió escribiendo con niveles de concentración que nunca antes había tenido en su patria, por mucho que la precariedad de sus ingresos lo obligaran a repetir la picaresca de la sobrevivencia, en términos parecidos a los que habían sido sus inicios en el periodismo, cinco o seis años antes.

No cabe la menor duda que La hojarasca es una novela fundacional en muchos sentidos. En realidad, se trata de un gran anticipo del García Márquez que vendrá, con Macondo como espacio de ficción, con sus guerras civiles y sus coroneles incluidos, con su noción del tiempo cíclico y con sus evidentes atisbos de eso que se llamará más tarde realismo mágico. La novela, que es corta y se deja leer con facilidad, salió bajo el sello de una editorial pequeña, con una tirada de cuatro mil ejemplares, lo que en Chile es un volumen del que parten sólo

\footnotetext{
${ }^{6}$ Martin, Gabriel García Márquez, 241.
} 
los autores más acreditados, en ningún caso los debutantes. El escritor asegura no haber recibido jamás un céntimo por los derechos de autor de la obra y admite que es probable que parte importante del tiraje inicial haya quedado en bodega, no obstante que La hojarasca tuvo buena acogida a nivel de crítica y reseñas en la prensa.

Pero fue con su segundo libro, El coronel no tiene quien le escriba, que García Márquez obtuvo una carta de ciudadanía literaria que rara vez los escritores latinoamericanos adquieren con tanta autoridad y tan al comienzo de su carrera.

En realidad, se trata de una pequeña joya. Es una novela breve, movida por un admirable sentido de la economía literaria que García Márquez sólo volvería a recuperar años después, con la Crónica de una muerte anunciada, y de equilibrios internos perfectos. Aunque el escenario no es Macondo, se le parece. Se trata de una villa de la costa atlántica colombiana, donde un coronel envejecido, debilitado y septuagenario baja todos los viernes al pueblo a preguntar por la pensión de veterano que un día le prometieron. Las cosas no han ido bien para el protagonista. Su mujer está asmática y tiene un hijo difunto que le dejó un gallo. Un gallo de pelea que requiere alimentos que el coronel no está en condiciones de proporcionarle, aunque el animal puede valer una pequeña fortuna y podría arreglarle su economía si llegara a ganar en las competencias de riñas de gallo previstas para unos meses más. Eso es todo. Hay poco más en esta narración lineal y de ensoñada impronta lírica. Hay un funeral en el pueblo, hay un médico, hay un señor poderoso que se le ofrece intermediar en la venta del gallo, están los que fueron amigos de su hijo... Y está por supuesto ese gallo solitario en el patio, venido a menos, cada vez más flaco, hambreado porque no lo están alimentando con maíz sino con habichuelas viejas, y que parece ser demasiado frágil para darle soporte a las cavilaciones y expectativas terminales de su dueño.

Los libros que publicó a continuación fueron primero una novela corta y luego un volumen de cuentos. Ambos son de 1962. La novela corta es La mala hora y quiere ser la radiografía de un pueblo que está pasando por un trance difícil tras la victoria del bando conservador en otro eslabón más de la interminable guerra civil colombiana. La atmósfera está enrarecida y sobre el pueblo soplan vientos tóxicos. Habrá un asesinato y circularán pasquines anónimos que saben demasiado 
y que recogen por igual medias verdades y medias mentiras. Aunque hay algunos personajes perfilados con relativa claridad, La mala hora entrega un curioso modelo de protagonismo colectivo y la narración plantea temas relacionados con el poder, la injusticia y la resignación. Muy importantes son también las condiciones atmosféricas en medio de las cuales tienen lugar los hechos: cae un diluvio, que está obligando al desplazamiento de los campesinos, y una ola insoportable de calor lo está descomponiendo todo.

En el libro de cuentos Los funerales de la Mamá Grande, García Márquez reunió siete relatos, en varios de los cuales aparecen personajes y motivos que sus novelas van a desarrollar con mayor profundidad después o que incluso ya habían aparecido en sus libros anteriores, como es el caso de la viuda de Montiel, que protagoniza aquí un cuento y que ya estaba en La mala hora, o como es el dolor de muelas que afecta al alcalde de esta novela y que reaparece aquí en el cuento "Un día de estos", donde el dentista le extrae sin anestesia una muela a una autoridad política contra quien tiene cargos de despotismo y asesinatos. El último cuento, que le da título al libro, es más bien una nouvelle, una novela corta, y es sobre todo un brillante ejercicio de la hipérbole. Ha muerto la gran matriarca de Macondo, la mujer que fue la dueña de todo y cuyos caprichos y decisiones constituyeron ley, y ahora la están enterrando. Viene no solo el Presidente de la República, sino también el Papa. La cosa es muy en grande porque se están yendo los tiempos míticos y arcaicos, y eventualmente podría estar llegando la modernidad.

La publicación de Cien años de soledad, en 1967, convertiría de alguna manera estos libros, estos relatos, en buenos ensayos y quizás también en espléndidos borradores. Lo más impresionante de estas narraciones es que dejan muy a la vista la cocina en la cual se fueron guisando a fuego lento los temas de la violencia y el despotismo, de la familia y los clanes dinásticos, del tiempo arcaico y el tiempo nuevo, de la guerra civil y sus coroneles, del machismo y el matriarcado, de la historia y la prehistoria, de la política y sus perversiones, de la democracia y sus maridajes, del gentío y la soledad, de la edad dorada y sus nostalgias y del presente paupérrimo y sus miserias, todo lo cual encontró expresión cenital en esta obra definitiva y mayor. La novela es la suma de todo eso, "el paquete" lo llamó él mismo, filtrado por la experiencia familiar y biográfica de García Márquez. 
Cien años de soledad fue un acontecimiento, un hito, una piedra que dividiría para siempre las aguas en las letras de nuestra lengua. Sucesos así se han visto pocos en la historia de la literatura. Esta novela quebró todos los estándares. Barrió literalmente con las cifras y dimensiones del mercado editorial latinoamericano. Hizo leer a gente que posiblemente jamás había leído un libro que se empinara por sobre las cien páginas. Se transformó en estandarte de un fenómeno editorial, el Boom, que adquirió de la noche a la mañana dignidad y estatuto literarios. Le entregó a América Latina una carta de identidad que hasta ese momento quizás ningún libro -ni siquiera expresiones especialmente influyentes, como el Ariel de José Enrique Rodó, El laberinto de la soledad de Octavio Paz e incluso ese poema continental que es el Canto general de Neruda - había logrado recoger e interpretar con tan amplio consenso.

Para quienes devoraron literalmente sus primeras ediciones, Cien años de soledad tuvo algo de shock. La experiencia estaba asociada a dos factores. En primer lugar, estaba asociada al poder hipnótico de la prosa de García Márquez, a su fosforescencia, a su esplendor verbal, a su manejo de la metáfora y la exageración, a su incomparable musicalidad interna, labrada muchas veces con endecasílabos o alejandrinos majestuosos. Álvaro Enrigue publicó en Letras Libres un buen artículo sobre la conexión de la prosa de García Márquez con la sonoridad de la poesía, en especial con Darío y Juan Ramón Jiménez?

El segundo factor tuvo que ver con la sorpresa: ¿cómo no habíamos visto lo que García Márquez nos hizo ver? Esto es típico, porque precisamente ésa es una de las funciones del arte. ¿Cómo no habíamos reparado que eran parte nuestra ciertas maneras de contar, ciertas matrices narrativas ancestrales, las cuales no sólo estaban profundamente arraigadas en nuestro idioma, el mismo de Cervantes, Darío y Neruda, sino que podían ser rastreadas con facilidad con sólo escarbar un poco la realidad demográfica de la región? Bastaba rascar dos o tres generaciones para atrás para dar con una cultura arcaica, campesina la mayoría de las veces, que — lo quisiéramos o no - seguía interpelándonos desde muy adentro.

Para esa generación, la de los 60 y 70, Cien años de soledad también fue importante por otro concepto: porque el libro fue portador de

\footnotetext{
7 Álvaro Enrigue, “Teoría de la persistencia”, Letras Libres, junio de 2014.
} 
una prosa y una poética que nos conectó con la majestad verbal del Siglo de Oro, con Cervantes, pero también con el modernismo de Darío; que redescubrió esa erótica narrativa que tuvo en la infancia para nosotros Las mil y una noches y que nos devolvió el gozo del idioma materno, idioma un tanto empobrecido en estas latitudes tras haber sido rehén por demasiado tiempo, al menos como lectores, de libros traducidos a lo mejor con exactitud pero sin belleza.

La novela de García Márquez nos paseó también por nuestro mestizaje cultural, por nuestras contradicciones, por nuestras raíces atávicas, por nuestra conexión con el tiempo mítico y por los temores que siempre ha inspirado en América Latina la modernidad.

La versión oficial —o mejor dicho, el mito urbano- es que García Márquez escribió su novela encerrándose en su casa de Ciudad de México por espacio de 18 meses seguidos después de una epifanía que tuvo mientras conducía un automóvil Opel con destino a Acapulco, adonde llevaba a su familia de vacaciones, momento en que se le aparece, por decirlo así, la oración que abre el libro ("Muchos años después, frente al pelotón de fusilamiento, el coronel Aureliano Buendía había de recordar aquella tarde remota en que su padre lo llevó a conocer el hielo.”). Pero no sólo la cautela sino también el sentido común obligan a tomar distancia de esta simplificación. Las cosas no deben haber sido $\tan$ sencillas.

Está bien: alguna iluminación o algo así puede haber ocurrido en el curso de ese viaje, pero lo cierto es que a su autor la novela le tomó más de quince años de trabajo. Un académico de Harvard, Álvaro Santana Acuña $^{8}$, asegura que en realidad la novela partió en 1950, cuando el escritor tenía 23 años, e invoca como prueba la publicación por parte de García Márquez en la revista colombiana Crónica de un texto que lleva por título La casa de los Buendía (Apuntes para una novela), donde, además de la casa familiar, se presentaba a uno de los personajes protagónicos de la novela y se entregaban pistas de la atmósfera sofocante de Macondo. El planteamiento del académico es que García Márquez trabajó como periodista durante quince años en seis países cargando con él de un lado a otro un manuscrito de 700 cuartillas titulado La casa.

${ }^{8}$ Véase el dossier de Álvaro Santana Acuña, "Una historia oculta de Cien años de soledad", Nexos, mayo de 2014. 
Comoquiera que sea, responda Cien años de soledad a las leyes de la inspiración fulminante o a las del trabajo sostenido y paciente durante años, cosa sobre la cual el debate puede ser interminable, lo que sí está claro es que pocas novelas se han escrito en la región que hayan tenido una campaña promocional tan anticipada - ya se estaba hablando de ella un año antes de aparecer-y pocas también surgieron de un contexto tan protegido como el que le ofreció Carmen Balcells al autor. El hecho es casi enigmático, porque a esas alturas García Márquez tenía la sensación de ser un escritor fracasado.

Santana dice que García Márquez llevaba consigo el manuscrito de su novela cuando el año 61 debió abandonar Nueva York por razones políticas. Había sido nombrado poco antes, ese mismo año, corresponsal de Prensa Latina, la agencia cubana de noticias creada por Fidel Castro después de la revolución, y se vino de vuelta por tierra con su familia a Ciudad de México. Su idea era reinventarse. Quiso ser guionista de cine. Tuvo que empezar a escribir en revistas de actualidad bajo otro nombre. Incluso trabajó como publicista en dos acreditadas firmas norteamericanas, J. Walter Thompson y McCann-Erikson. Si bien nada de esto era muy seguro y definitivo, el problema que evaluó fue que podía llegar a serlo y que eso podía significar despedirse para siempre de la literatura.

El viento habría cambiado en ciento ochenta grados para él cuando Álvaro Mutis, su amigo, lo contacta con un grupo de artistas conocido como "La mafia", y que, encabezado por Carlos Fuentes, reunía también a Buñuel y Rulfo entre sus miembros. A partir de ahí habría sobrevenido el cambio de fortuna. Porque las actividades del grupo atrajeron la atención del benefactor Rodman Rockefeller, del editor Alfred Knopf, que publicó varios de los títulos del Boom en Estados Unidos, y de la agencia literaria de Carmen Balcells, que le ofreció al escritor un contrato — no se pierdan — por ciento cincuenta años. Lo cierto, según Santana, es que al día siguiente de suscrito ese contrato García Márquez se puso de cabeza a trabajar en la última versión de la novela. El escritor habría terminado esa versión entre julio de 1965 y agosto de 1966. Pero para entonces la campaña promocional ya estaba en marcha.

Ésta es una novela que se promociona tres meses antes de que su autor la haya terminado. Esto claramente es muy infrecuente en las prácticas de la industria editorial y parece la trama de una novela 
policíaca de contornos conspirativos. Es interesante, es novelesco, es también un poco delirante, pensar en el Boom latinoamericano como en una conspiración. Hay muchos antecedentes y coincidencias que dan para pensar algo así. El pensamiento paranoico tiene aquí una cantera para explotar los próximos cien años. Lo importante, sin embargo, no es eso, sino cómo - sin mayor aviso y en un período tan corto- la literatura latinoamericana se pega literalmente un estirón que termina colocando a lo menos a cuatro de los autores más representativos del fenómeno — García Márquez, Cortázar, Carlos Fuentes y Vargas Llosa- en el Olimpo de nuestra letras. Conjuntamente con eso, el Boom expandiría y multiplicaría por cuatro o cinco veces el mercado editorial, conquistaría nuevas audiencias y lectores para la literatura latinoamericana y renovaría con notable energía la conversación y el debate sobre la identidad cultural de la región.

Son muchas las explicaciones e interpretaciones que se han dado del Boom. Algunas muy académicas, otras muy personales ${ }^{9}$. Ninguna posiblemente es la definitiva. Fue una suerte de golpe de Estado literario. ¿O fue una conjunción astral? La pregunta es qué ocurrió, qué posibilitó que las circunstancias históricas objetivas se juntaran con las ganas. Qué hizo que el discurso literario se cruzara con tanto provecho con el discurso político. Qué pesó para que la más pobre de las industrias de la región — la industria editorial - reclamara de la noche a la mañana un protagonismo que nunca había tenido y que en estricto rigor jamás volvió a tener.

\section{IV}

El éxito de Cien años de soledad, como no podía ser menos, puso a García Márquez en otra galaxia. Lo llevó a irse por un tiempo a Barcelona y lo sacó del nicho donde siempre se había movido - la bohemia literaria, la picaresca de la marginalidad, la sempiterna necesidad de cuadrar las cuentas a fin de mes-, instalándolo en los circuitos de la

${ }^{9}$ Una buena sistematización de las perspectivas académicas se encuentra en Ángel Rama, La novela en América Latina. Panorama 1920-1980 (Santiago: Ediciones Universidad Alberto Hurtado, 2008). Para un prisma más personal —delicioso, subjetivo- - el libro de José Donoso, Historia personal del Boom (Santiago: Alfaguara, 2007), es una fuente de rigor. 
fama y el poder. Era ahí donde siempre había querido estar. Es posible que hubiera querido mucho más eso que el reconocimiento o la adoración por parte de las capillas literarias.

Puede ser un abuso interpretar una biografía a partir de un solo momento, más todavía cuando difícilmente un episodio aislado puede servir para evaluar retrospectivamente toda una vida. En el caso de García Márquez, la tentación, sin embargo, es muy grande. García Márquez, en el fondo, eligió con mucho cuidado el tipo de vida que quería tener y el tipo de figura que quería llegar a representar. Tal vez nunca titubeó; en los peores momentos se vio como un fracasado, pero jamás claudicó. En más de un sentido, García Márquez se mandó "a hacer". Trabajó muy duro convertirse en un gran narrador: leyó montañas de libros, aprendió de poesía como un salvaje y fue puliendo y trabajando su prosa con la destreza de un artesano, la levedad de un carterista y la paciencia de un relojero. Todo eso es trabajo, mucho trabajo. Él mismo lo reconoció en el prólogo de una curiosa antología de cuentos que reunió un relato suyo junto a piezas de Mario Benedetti, Rodolfo Walsh, Silvina Bullrich, Manuel Mujica Láinez y David Viñas, entre otros autores, cuál de todo más diferente: "He tenido que someterme a una disciplina atroz para terminar media página en ocho horas de trabajo. Peleo a trompadas con cada palabra y casi siempre es ella quien sale ganando, pero soy tan testarudo que he logrado publicar cuatro libros en veinte años" 10 .

Su idea, por así decirlo, no era sólo ser un gran escritor, era ser un escritor de convocatoria muy masiva, porque de otro modo no iba a poder desplegar mayores redes hacia el mundo del poder, que siempre le había intrigado, fascinado, seducido o hechizado.

En simple, García Márquez "se construyó" a sí mismo de manera parecida a lo que hizo Neruda para convertirse, especialmente después del Canto general, en el gran poeta de América Latina; o a la que intentó Jean Paul Sartre queriendo ser el gran filósofo, el gran referente intelectual de la izquierda, el rector del pensamiento crítico y contestatario del siglo XX. En el caso de los tres es posible advertir una cierta estrella — qué duda cabe que los tres son hijos de su época-, pero

${ }^{10}$ Citado por Javier Fernández García, "El otoño del patriarca: Germen de una novela", Cauce 16, Centro Virtual Cervantes. La antología de cuentos se titula Los diez mandamientos (Buenos Aires: Ed. Jorge Álvarez, 1976). 
también es posible advertir, además de una notable capacidad para leer el contexto histórico, una cuota no menor de construcción y cálculo. Estos íconos culturales, esta forma de magisterio artístico y cívico es un producto muy propio de la segunda mitad del siglo XX, cuando fueron muchos los escritores que brillaron en el rol del intelectual público, un poco como los sabios de la tribu, un poco como guardianes de la conciencia crítica y moral de la sociedad.

Que García Márquez haya podido instalarse ahí es doblemente meritorio, porque él pertenece a la tradición menos intelectual de la literatura latinoamericana. Nunca escribió ensayos propiamente literarios y nunca reflexionó muy en serio o en abstracto sobre su trabajo, sobre el de los demás escritores o sobre los dominios del lenguaje o los límites de la ficción. No obstante eso, se metió sin saberlo ni quererlo, en los pantanos y berenjenales teóricos de las estructuras de narración. La diferencia es que llegó hasta allí no con el instrumental de un analista que reflexiona sino arrastrado, como las bestias en busca de pastos más verdes, por una fantasía bullente de escritor imaginativo y silvestre. García Márquez tiene mucho de animal literario: convertía en relato todo lo que tocaba, pero huía de especulaciones académicas como de la peste y se manejaba poco en grandes teorías, lo cual constituía una verdadera excentricidad en una época en que el ambiente literario latinoamericano se llenó de complejas construcciones intelectuales y de una apestosa hermenéutica estructuralista-político-cultural. Su carta de presentación nunca fue la disquisición académica ni el vuelo teórico. Fueron más bien el placer de contar historias y el de transmitir los fuegos de la emoción.

Ocho años después de Cien años de soledad, García Márquez entregó otra novela igualmente fascinante, pero que atrapa al lector con menor intensidad, en gran medida porque está menos lograda: El otoño del patriarca.

No obstante que comparte algunos rasgos con la novela capital de su autor, El otoño del patriarca es muy diferente. Se diría que su autor hizo un arduo esfuerzo para ponerse a cubierto de la bien probable acusación de estar repitiéndose, una crítica que en realidad pocos autores toleran bien. El escritor quería demostrar que no estaba entrampado ni en el estilo ni el mundo poético de Cien años de soledad. Es cierto que El otoño del patriarca respira un clima dramático y moral que es 
parecido. Nuevamente, el tiempo mítico tiene mucha más fuerza que el tiempo real. El patriarca ha vivido como trescientos años y tiene algo de inmortal, incluso después de muerto. Pero la inspiración y el emplazamiento aquí son más atlánticos y caribeños, y formalmente es una novela más compleja, difícil y jugada. Se ha perdido el relato clásico y más bien convencional de Cien años de soledad. En El otoño... escuchamos una voz que nunca sabemos con certeza a quién corresponde. El patriarca ya ha muerto y por su casa circulan cerdos, ratas y gallinazos. A veces lo que leemos son los delirios del dictador agónico, a veces es la voz de la madre, en otras se distingue más bien a su mujer, una novicia que llega a manejar una importante cuota de poder. Casi no hay puntos y apartes, y tramos completos discurren sin un solo punto seguido. El primer párrafo tiene nada menos que 87 páginas. Como no podía ser de otro modo, la narración es bastante más interior, no obstante que se van recomponiendo a jirones pasajes de la vida del patriarca, hitos de su captura del poder total y de su larga dictadura demencial. En 1981, conversando con su amigo Plinio Apuleyo Mendoza, García Márquez describió El otoño... como “un poema sobre la soledad del poder"11.

Obra muy "faulkneriana", muy entregada a los flujos de conciencia y a frases barrocas e interminables, El otoño del patriarca es una novela reveladora sobre todo por la concepción del poder en que el escritor sustentó la narración. Para García Márquez, el poder designa una instancia de plenitud, que explica no sólo la impermeabilidad de este relato al juicio ético de la política, sino también la fascinación que siente el escritor por las formas más estrafalarias y crueles del ejercicio del poder cuando éste no tiene límites.

Aunque la novela se inscribe en una robusta tradición literaria y reflexiva acerca de la figura del dictador - donde destacan El reino de este mundo (Carpentier), El señor presidente (Asturias), Yo, el supremo (Roa Bastos) o La fiesta del Chivo (Vargas Llosa), publicada mucho después-, la de García Márquez está muy lejos de ser una obra de contornos críticos. Todo lo contrario. Ésta es más bien una exaltación, una mirada compasiva al dictador, a su soledad, a su envejecimiento y,

${ }^{11}$ Citado por Enrique Krauze en "Gabriel García Márquez. A la sombra del patriarca", Letras Libres, octubre 2009. Disponible en http://www.letraslibres.com/ revista/convivio/gabriel-garcia-marquez-la-sombra-del-patriarca?page=full. 
sobre todo, a sus delirios y paranoias ante el temor de llegar a ser traicionado por los suyos.

Vaya que hay paño político para cortar a partir de este prisma. La estructura y la moral de El otoño del patriarca entrega un amplio margen a la indignación: "Si García Márquez — escribe Enrique Krauze, a partir de su reseña al libro de Martin - se acerca al déspota no es para exponer o juzgar la complejidad interior de un hombre de Estado sino para inducir compasión por un pobre diablo, viejo y solitario. El dictador es una víctima de la Iglesia, los Estados Unidos, el desamor, los enemigos, los colaboradores, las catástrofes naturales, las inclemencias de la salud, la ignorancia ancestral, la fatalidad, la orfandad. Un caso extremo: después de violar a una mujer, ello lo consuela. Otro más: la casa de retiro para los dictadores caídos en desgracia, que dedican las tardes de su exilio al dominó. La nostalgia les asegura la impunidad. La misma novela que desdibuja la realidad del poder y deshumaniza a las víctimas convierte la dictadura en un melodrama y humaniza al dictador" 12 .

Gerald Martin plantea una perspectiva de análisis extremadamente desafiante cuando en su biografía dice que tal como Cien años de soledad es una novela-eje respecto de la vida del escritor, El otoño del patriarca es la novela-eje respecto de su obra.

"En cierto sentido - escribe Martin - es El otoño del patriarca, y no Cien años de soledad, la obra decisiva de la carrera de García Márquez como escritor, porque, contrariamente a lo que pudiera parecer a primera vista, en ella se compendian todas sus otras obras. Se considere o no su "mejor" novela, como el mismo García Márquez ha afirmado con frecuencia, no cuesta entender por qué cree que es, en cambio, la 'más importante', sobre todo si añadimos a esa condensación otros dos rasgos ya mencionados: la insistencia en que el Patriarca es un retrato del propio Gabo y el hecho de que escribió el libro para 'demostrarse a sí mismo' su condición de autor tras el éxito extraordinario de Cien años de soledad. Puede decirse, pues, que en tanto Cien años de soledad es sin duda el eje de su vida (y el libro más importante en relación con el resto del mundo, y tal vez también en relación con su posteridad), El otoño del patriarca es el eje central de su obra: después de esta

\footnotetext{
12 Krauze, "A la sombra".
} 
novela, irónicamente, la naturaleza devoradora de su obsesión literaria con el poder tocaría a su fin, en el instante mismo en que el poder se convertiría en el asunto central de su vida"13.

\section{V}

La relación de García Márquez con el mundo del poder corresponde a uno de los aspectos más impenetrables, oscuros y difíciles de entender de su vida. El tema tiene a veces contornos que son entre humillantes y sórdidos. Lo más curioso es que siendo un hombre de clara sensibilidad de izquierda - marcado por una fuerte conciencia antiimperialista y por la masacre en que culminó, a comienzos del siglo XX en Aracataca, una huelga de trabajadores de la United Fruit-, García Márquez jamás fue un escritor político. Tenía sus opiniones, sí, pero tenía muy claro que el oficio literario lo situaba en un plano muy distinto al de las contingencias de la vida pública. Sus amigos recuerdan que jamás en España se involucró en las actividades de resistencia al régimen de Franco, no obstante que es cierto que cuando recién comenzaba a estudiar derecho en Bogotá había trabajado por la causa de Gaitán.

La ansiedad por la política en su caso fue muy tardía. Mucho contribuyó a ella la caída de Salvador Allende y la instalación de una dictadura militar en Chile. El escritor envió el mismo 11 de septiembre un telegrama a los miembros de la junta militar de repudio al nuevo régimen ${ }^{14}$. Sin embargo, no fue sino hasta después de la publicación de $E l$ otoño... cuando incorpora a su radar la necesidad, la compulsión, de acceder y tender puentes hacia los poderosos. La pieza mayor en su mira era Fidel Castro, y vaya que le costó capturarlo. García Márquez había sido muy cuidadoso de no romper ninguna de sus líneas de contacto con La Habana con ocasión del caso Padilla, cuando el poeta Heberto Padilla fue obligado a representar públicamente un penoso libreto de autocrítica que recordó las prácticas del estalinismo durante los llama-

${ }^{13}$ Martin, Gabriel García Márquez, 429.

${ }^{14}$ El texto es el siguiente: "Bogotá, 11 de septiembre de 1973. Generales Augusto Pinochet, Gustavo Leigh, César Mendoza y almirante José Toribio Merino, miembros de la junta militar: Ustedes son autores materiales de la muerte del Presidente Salvador Allende y el pueblo chileno no permitirá nunca que lo gobierne una cuadrilla de criminales a sueldo del imperialismo norteamericano"; Martin, Gabriel García Márquez, 421. 
dos Procesos de Moscú. Su autoinculpación tuvo lugar tras haber estado en la cárcel durante 38 días. A partir de ahí se convirtió en un ser fantasmal. Lo dejaron salir de Cuba recién a mediados de marzo de 1980, gracias a la presión internacional y a las gestiones del senador Edward Kennedy. Lo suyo había sido un espectáculo obsceno que mereció el reproche mundial de intelectuales de la estatura de Jean-Paul Sartre, Simone de Beauvoir, Octavio Paz, Alberto Moravia, Susan Sontag, Julio Cortázar, Marguerite Duras, Carlos Fuentes, Mario Vargas Llosa, Hans Magnus Enzenberger, Jorge Edwards y Juan Goytisolo. García Márquez fue uno de los pocos que se sustrajo y Cortázar posiblemente el único que después de haber firmado la carta de protesta abjuró, simplemente porque no pudo tolerar el desprecio de Castro. De suerte que el nombre de García Márquez estaba "limpio" a los ojos del castrismo. Así y todo, le costó llegar a Fidel en 1976. Para entonces, aparte de haber escrito contra el golpe militar chileno, había rendido numerosas pruebas de incondicionalidad a la revolución. También se había ofrecido a escribir sobre la aventura cubana para la "liberación" de África y conversó al respecto con interlocutores duros del régimen, como Lisandro Otero, agregado cultural cubano en Londres en ese momento, el escritor que le tendió la trampa a Heberto Padilla, o el propio Carlos Rafael Rodríguez, el ministro cubano de asuntos exteriores. En ese momento la revolución se estaba radicalizando. Al final, el encuentro con Fidel se produjo. García Márquez pasó, sin embargo, un mes en el Hotel Nacional de La Habana esperando la ansiada llamada del comandante. Fue un tanto humillante. Hasta que un día apareció un jeep como a las tres de la tarde y Fidel lo invitó a dar un paseo por las inmediaciones de la capital cubana. García Márquez dice que hablaron de comida y de la industria alimentaria. Iba con Gonzalo, su hijo menor, que se sentó atrás. Cuando lo devolvió al hotel dos o tres horas después, le dijo que invitara a su señora Mercedes para la próxima y que cuando llegara le avisara a su hermano Raúl, jefe de las fuerzas armadas revolucionarias, para dar forma a ese artículo sobre Cuba en África que había ofrecido escribir. Mercedes Barcha llegó al día siguiente, notificaron a Raúl, pero la pareja tuvo que esperar otro mes a que los recibiera y comenzara a proporcionarle al escritor insumos para escribir su artículo sobre la epopeya del ejército cubano en Angola. Después de eso - y de su comedida gentileza de enviarle a Fidel lo que escribió para que lo revisara, 
cosa que volvió a tomar semanas y semanas de impaciencia-, García Márquez generó con el líder de la revolución cubana - de creerle a él- "una de las amistades literarias" más hermosas del mundo, porque de eso, de libros, es de lo que hablaban, y así el autor de Cien años de soledad se convirtió en una de las pocas amistades masculinas que Fidel Castro tuvo después del Che Guevara y de Camilo Cienfuegos. Hay que decirlo: la amistad fue una flor escasa en el entorno del padre de la revolución cubana. Escasa y peligrosa, como lo pudieron comprobar después el general Arnaldo Ochoa y los hermanos Tony y Patricio La Guardia.

La obstinación por conseguir la amistad de Castro — antes había logrado otro tanto con Omar Torrijos y seguiría sumando poderosos con Mitterrand, Felipe González, López Michelsen, Daniel Ortega, López Portillo, Bill Clinton, César Gaviria o incluso un político conservador como el Presidente Andrés Pastrana ${ }^{15}$ - es extraña y mueve al observador a preguntar de qué estaba huyendo García Márquez al forjar y mantener estas relaciones. Con el único que no simpatizó ni enganchó fue con el comandante Hugo Chávez. La pregunta sobre el origen de su obsecuencia al poder es pertinente, porque ninguna de estas amistades, descontada quizás la de Castro — que lo instalaba en América Latina como el escritor preferido de la revolución cubana, que era lo que él quería-, agregaba gran cosa a su prestigio. Al contrario, ponía su figura en entredicho. ¿Era necesario traspasar así los límites de la decencia y la verdad? Escribe Enrique Krauze: "En los tres famosos reportajes titulados 'Cuba de cabo a rabo', García Márquez describió su epifanía: vio la abundancia universal, omitió la presencia de los rusos, alabó los sistemas de vigilancia revolucionaria 'para que todo el mundo sepa quién es y qué hace el vecino, celebró 'la instauración del poder popular mediante el voto universal y secreto desde la edad de dieciséis años', pero sobre todo vio 'el sistema de comunicación casi telepática' que Fidel había establecido con la gente. 'Su mirada delataba la de-

${ }^{15}$ Fui sorprendido por el nexo entre García Márquez y el Presidente Pastrana estando en la casa de Andrés Allamand en Washington a mediados de 1999. Yo estaba trabajando en la edición del libro La travesía del desierto, de Allamand. El escritor y su señora le hicieron una visita a su casa; eran amigos desde hacía años. Ahí me enteré de que García Márquez había escrito el discurso de asunción del mando de Andrés Pastrana. Tanto como eso, me sorprendió que ni García Márquez ni Allamand parecían haber quedado muy conformes con esa pieza de oratoria. 
bilidad recóndita de un corazón infantil [...], ha sobrevivido intacto a la corrosión insidiosa y feroz del poder cotidiano, a su podredumbre secreta $[\ldots]$ ha dispuesto todo un sistema defensivo contra el culto a la personalidad""16. La pregunta se vuelve obsesiva: ¿era necesario tanto?

Ha de reconocerse, sí, que su familiaridad con los poderosos lo convirtió circunstancialmente en un buen agente o mediador para asuntos tales como la devolución del canal a los panameños, la liberación de algunos presos en las cárceles cubanas, los contactos del gobierno colombiano con la guerrilla, las facilidades de los estadounidenses para ir a Cuba, medidas administrativas para suavizar el bloqueo a Cuba o el desarrollo de campañas internacionales a favor de causas emblemáticas de la izquierda mundial.

La pulsión de García Márquez con el poder tiene algo de fascinación y algo también de herida. No sólo Gerald Martin sino muchos otros observadores y analistas sostienen que en la base de esta desviación está la figura patriarcal del abuelo, su muerte repentina a los pocos días de haberse caído de una escala mientras trataba de recuperar un loro que se había arrancado de su jaula. Para este niño de ocho años, ese accidente significó el término abrupto de lo que había sido una infancia dorada. El abuelo había sido su modelo y gran escudo protector. Después de eso, el niño queda al cuidado de las mujeres de la casa y prácticamente desaparece de su vida la figura masculina. El de García Márquez fue un padre un tanto errático y ausente. Sea o no sea válida esta explicación, lo cierto es que es la más difundida. Posiblemente hay que ser psicoanalista para entenderla en todos sus alcances.

Lo más significativo, a todo esto, es que no obstante la amistad con Castro y no obstante la simpatía y línea directa que mantuvo con figuras políticas prominentes de la escena mundial, García Márquez en ningún momento se convirtió en otro de los grandes intelectuales públicos que por entonces todavía quedaban en América Latina. Nunca fue un Carlos Fuentes, tampoco un Vargas Llosa. Menos un Octavio Paz. Dios nos libre de un santón malas pulgas como Saramago. Lo concreto es que en los grandes temas políticos de nuestro tiempo - la igualdad, la libertad, la democracia, la globalización, las instituciones, la gobernabilidad, el desarrollo — nunca dictó cátedra de nada.

16 Enrique Krauze, “Gabriel García Márquez, el romance del poder”, Letras Libres, junio de 2014. 
A García Márquez — qué duda puede caber- le interesaba el poder. Pero no el poder de las ideas, sino el poder fáctico.

\section{$\mathrm{VI}$}

Cuando murió este año, el jueves 17 de abril de 2014, Gabriel García Márquez tenía 87 años y hacía por lo menos una década que ya no estaba escribiendo. Su última novela fue Memoria de mis putas tristes, que dejó incluso entre sus lectores más incondicionales la sensación incómoda de un talento declinante.

Autor de obras que ya tienen aliento clásico - desde El coronel no tiene quien le escriba (1961) a El amor en los tiempos del cólera (1985), desde Cien años de soledad (1967) a la Crónica de una muerte anunciada (1981), desde El general en su laberinto (1989) hasta su hermoso libro de memorias, que cubre el período de su infancia y juventud, Vivir para contarla (2002) - García Márquez es también autor de varios excepcionales libros de cuentos y de seis o siete volúmenes que recogen su producción periodística. La matriz periodística — porque se trata de un largo, exhaustivo y excelente reportaje - también está presente en Noticia de un secuestro (1996), donde investigó y recreó, en un relato vibrante y de respiración cardíaca, el secuestro de un grupo de periodistas, camarógrafos y directivos de medios de comunicación colombianos por parte de una banda asociada a las redes narcoterroristas de Los Extraditables.

Si van a ser — por decirlo así- sus libros más pequeños, como éste, como El coronel no tiene quien le escriba o como la magnífica Crónica de una muerte anunciada, los que mejor van a sustentar su nombre de cara a la posteridad, o si, por la inversa, García Márquez seguirá siendo básicamente Cien años de soledad, El otoño..., El amor en los tiempos del cólera, es decir, sus novelas mayores, es una conjetura difícil de responder por el momento. No faltan los que dicen que el poder hipnótico que tuvo Cien años de soledad para quienes la leímos en 1970 se ha desgastado. Obvio, la sorpresa, el resplandor verbal, la convulsión poética que en su momento pareció destaparse desde las profundidades con la fuerza de un volcán ya no son los mismos. Algo sugiere que los lectores de la posmodernidad ya no están para sagas tan vastas y que a muchos lectores jóvenes el libro tiende a caérseles de las 
manos. Los Cien años de soledad están bien, pero le sobraron veinte o treinta, habría dicho Borges (según Krauze).

Si lo que buscamos en la literatura no es sólo fugarnos a los mundos de la ficción sino también reconocernos - reconocernos en lo que somos, en el mundo que vivimos, en los problemas que afrontamos-, el tiempo quizás va a correr en contra de García Márquez. El suyo, el de sus novelas, el de Macondo y sus coroneles, es un tiempo ido. Sus diluvios, hechiceros y gallinazos le dicen poco a un amplio público generalmente joven - cruzado por las disociaciones de la modernidad. Como escribió Alberto Fuguet en Tránsitos: "El nuevo realismo no tiene que ver con gente que vuela sino con lo volada que está la gente. [...] Los artistas, en especial los escritores, tienen el deber moral de narrar historias que de alguna manera recojan el país real, no el mítico"17. Fuguet fue uno de los primeros escritores jóvenes de América Latina que exhortó a la rebelión contra el realismo mágico y $\mathrm{McOndo}$, el volumen de cuentos que editó junto a Sergio Gómez para Grijalbo el año 1996, fue tanto un manifiesto como una profanación. Hoy, cuando ya es mucha el agua que ha pasado bajo los puentes, surge la duda de si fue esto o aquello y lo cierto es que hoy el libro puede ser leído como lo que siempre fue: una antología más o menos feliz de cuentos de escritores jóvenes en andaban en busca de su propia voz e identidad.

Tal vez sea prematuro decir que García Márquez fue o no fue el genio de la literatura universal, como tituló El País en la edición especial que sacó al día siguiente de su muerte. Fueron 32 páginas de excepcional periodismo y un gran tributo al escritor desaparecido. ¿Volverá a merecer semejante honor algún escritor en los próximos veinte, cincuenta o cien años? ¿Estará perdiendo acaso poder de convocatoria la literatura, sobre todo ahora que las novelas, más que contar historias, se proponen básicamente desplegar "artefactos verbales"? Difícil saberlo.

García Márquez anexó a millones de lectores para la literatura pero, curiosamente, no dejó instalada ni una escuela ni verdaderos herederos. Los libros que en un momento se publicaron en América Latina rindiendo tributo o haciendo guiños al realismo mágico hoy en su mayor parte dan vergüenza ajena. No hay país de la región que haya sido inmune a esta peste. Fue una moda que, tal como llegó, se fue.

${ }^{17}$ Alberto Fuguet, Tránsitos (Santiago: Ediciones Universidad Diego Portales, 2013), 410 . 
No, no es cosa de agarrar la fórmula del realismo mágico en acción y espolvorear a discreción - como creyeron los incautos - luciérnagas fosforescentes, diluvios interminables, abuelas inmemoriales, putas desgañitadas, casonas en ruinas y gallinazos hambrientos. Dicen que donde mejor ha funcionado el realismo mágico es en Salman Rushdie, el autor de Los versos satánicos. Pero, con todo respeto, eso no es decir gran cosa.

Animal literario irreductible a pesar de sus flirteos con el poder, a pesar —incluso - de sus obsecuencias y bajezas, García Márquez bebió, asimiló y se nutrió de muchas fuentes. Faulkner, que había inventado Yoknapatawpha County como emplazamiento de sus ficciones, le enseñó a construir todo un pueblo como escenario de su mundo poético y le dio el pase para el monólogo interior, los saltos temporales y los flujos de conciencia. La poética de Rulfo le alumbró el camino para que descubriera el tinglado de creencias del campesinado latinoamericano pobre. Kafka le enseñó que lo extraño, lo extraordinario, lo monstruoso incluso, puede pasar a ser un dato del mundo cotidiano ${ }^{18}$. Hemingway le impartió lecciones de acción; pudo habérselas dado también para componer diálogos fluidos y punzantes, pero García Márquez habría reprobado este examen y por eso en sus libros hay poco diálogo. Respecto de Borges, la relación es más compleja. García Márquez dijo alguna vez que lo admiraba mucho pero le interesaba poco. Puede ser. Pertenecían a mundos demasiado diferentes. Borges, por lo demás, era un descreído de la novela como género literario para estos tiempos. La verdad es que son pocos los libros de García Márquez que eventualmente puedan compartir el sentido de la economía verbal del autor de El Aleph.

Héctor Aguilar Camín sostuvo que García Márquez era por lejos el mayor autor de las letras hispanas. No sólo eso. También dijo que era el más querido. Se hacía querer con su simpatía, con su liviandad, con la resistencia que ofrecía su humor para evitar los pecados de la arrogancia y la gravedad: "Nada me impresionó tanto en el trato del Gabo como la tranquilidad que fluía de su persona, su falta de prisa, la redonda calma que pasaba por la vida diciendo cosas inesperadas, inconfun-

18 Arturo Fontaine profundizó con especial lucidez en la imperturbabilidad del narrador como rasgo esencial de Cien años de soledad en su artículo sobre la novela, “¿Es una obra maestra?”, publicado en Artes y Letras de El Mercurio, 20 de abril de 2014. 
diblemente suyas. Por ejemplo: Lo malo de la vida no es que dure poco, sino que siempre termina igual y, además, se va muy rápido.

"Pensé mucho tiempo que aquella tranquilidad soberana era la conclusión de una vida cumplida: la serenidad de un hombre que nada más tenía que pedir a la vida. No es así, desde luego. Siempre hay algo más que pedirle a la vida.

"La parsimonia vital de García Márquez creo que era el fruto de un don aparte, el don de la concentración y la paciencia propias del artesano que alcanza la redondez de su vida en la redondez sin prisa de su oficio" $"$.

Fue muy querido, llegó lejos y cosechó amplios reconocimientos. El único plano que estuvo por debajo de su posición, de su nivel y de sus intereses fue el cine, que tanto le gustaba. Nada de lo que hizo él por sí, nada de lo que hicieron con su obra, que fue mucho y generó grandes expectativas en su momento, califica ni siquiera con benevolencia. Está bien: la prudencia recomienda que los plenos poderes tengan un límite.

Mucho antes que muriera, García Márquez ya estaba instalado muy arriba en los cielos de la literatura. Martin cree que su genialidad consistió en darle estatuto literario soberano a América Latina. Lo de antes pudieron ser buenas aproximaciones, pero a juicio suyo es con él que la poética de la región irrumpe en plenitud. Son muchos, partiendo por su biógrafo, quienes lo ponen a la altura de Cervantes. ¿Estará tan arriba, será comparable? Mucho antes de su distanciamiento, Vargas Llosa lo había llamado el Amadís de América. Carlos Fuentes fue más lejos y le reconoció estatura bíblica a su obra. Volpi lo compara con Dionisio, asumiendo que Borges es nuestro Apolo y que serían ellos dos, García Márquez, que se leyó mucho, y Borges, que hoy se lee poco, los dos colosos de la edad de oro de la literatura latinoamericana. Desde luego que hay razones para dudar de que les hubiera gustado compartir el honor.

Pueden ser atractivas estas tesis y dan ganas de suscribirlas eventualmente. Lo malo es que estas apuestas son demasiado inciertas. Si alguna lección queda después de leer Cien años de soledad es que hay que aprender a respetar el tiempo, sobre todo en estas latitudes. La úl-

${ }^{19}$ Héctor Aguilar Camín, "Una vida digna de su imaginario", Nexos, mayo de 2014. 
tima palabra la tendrá el tiempo. Ni siquiera sospechamos su dictamen. Si es por elegir las fichas que se han puesto sobre la mesa, pienso que no seríamos pocos los que nos sentiríamos mejor acompañados y más seguros con Borges. EP 